\title{
Potential Role of Proteasome Accessory Factor-C in Resistance against Second Line Drugs in Mycobacteria
}

\author{
Apoorva Narain ${ }^{1, \odot}$ Rikesh K. Dubey ${ }^{2}$ Ajay Kumar Verma ${ }^{1} \quad$ Anand Srivastava ${ }^{1} \quad$ Surya Kant
}

${ }^{1}$ Department of Respiratory Medicine, King George's Medical University, Lucknow, Uttar Pradesh, India

2Department of Microbiology, Central Drug Research Institute (CSIR), Lucknow, Uttar Pradesh, India

\begin{abstract}
Address for correspondence Surya Kant, MD, Professor and Head, Department of Respiratory Medicine, King George's Medical University, Shahmina Road Chowk, Lucknow 226003, Uttar Pradesh, India (e-mail: skantpulmed@gmail.com).
\end{abstract}

J Lab Physicians:2020;12:250-262

\begin{abstract}
Keywords

- mycobacteria

- PafC

- multidrug resistance

- fluoroquinolones

Objectives Mycobacterium tuberculosis (MTB), the causative agent of tuberculosis (TB), can survive inside the host granuloma courtesy the various extrinsic and intrinsic factors involved. Continuous use or misuse of the anti TB drugs over the years has led to the development of resistance in MTB against antibiotics. Drug-resistant TB in particular has been a menace since treating it requires exposing the patient to drugs for a prolonged period of time. Multidrug-resistant (MDR) and extensively drug resistant TB cases have increased over the years mostly due to the exposure of MTB to suboptimal levels of drug. Proteasomes provide MTB its pathogenicity and hence helps it to survive inside the host even in the presence of drugs.

Materials and Methods The recombinantly expressed proteasome accessory factor-C (PafC) protein was purified via Ni-NTA affinity chromatography and overexpressed in the nonpathogenic strain of mycobacteria (Mycobacterium smegmatis) for the comparative analysis of minimum inhibitory concentrations of antimycobacterial drugs. The bacteria were subjected to various stress conditions. Secretory nature of PafC was analyzed by probing the purified protein against patient sera. Quantitative mRNA analysis of pafC, lexA, and recA was performed to check for their level under fluoroquinolone (FQ) presence. The data were validated in clinical samples of pulmonary TB patients.

Results pafC, that forms one part of paf operon, is involved in providing MTB its resistance against FQs. Through a series of experiments, we established the fact that PafC is upregulated in mycobacteria upon exposure to FQs and it leads to the increased intracellular survival of mycobacteria under the stresses generated by FQs. The study also refers to the correlation of pafC to deoxyribonucleic acid (DNA) damage repair enzymes lexA and recA at transcriptional level. The results obtained in vitro corroborated when the pulmonary TB patients' samples were subjected to the same molecular analysis.

Statistical Analysis All experiments were conducted at least in triplicate. $p$-Value of $<0.05$ was considered to be statistically significant

Conclusion PafC plays a significant role in providing resistance to mycobacteria against FQ class of drugs by increasing its intracellular survival through increased drug efflux and getting involved with DNA damage repair machinery.
\end{abstract}

DOI https://doi.org/

10.1055/s-0040-1722552

ISSN 0974-2727.
(C)2020. The Indian Association of Laboratory Physicians.

This is an open access article published by Thieme under the terms of the Creative Commons Attribution-NonDerivative-NonCommercial-License, permitting copying and reproduction so long as the original work is given appropriate credit. Contents may not be used for commercial purposes, or adapted, remixed, transformed or built upon. (https://creativecommons.org/licenses/by-nc-nd/4.0/). Thieme Medical and Scientific Publishers Pvt. Ltd. A-12, 2nd Floor, Sector 2, Noida-201301 UP, India 


\section{Introduction}

Tuberculosis (TB) is caused by an aerobic, acid fast bacillus, Mycobacterium tuberculosis (MTB). In $80 \%$ of the cases bacteria infects the lungs causing pulmonary tuberculosis (PTB) whereas in the remaining $20 \%$ of cases it affects other organs causing extrapulmonary tuberculosis (EPTB). ${ }^{1}$ MTB could evade host defense system and persist inside the granuloma for long periods. It takes months to even years in some cases to completely eradicate the bacteria from the host. ${ }^{2,3}$ MTB over the course of its evolution has garnered various mechanisms like thick mycolic acid and fewer porins in the cell wall, drug efflux pumps, and proteasome machinery that impart it resistance against drugs. ${ }^{4-6}$ Fluoroquinolones (FQs) are the choice of drugs for treating the multidrug-resistant TB (MDR-TB) in patients when the first line treatment fails. MDR strains of MTB are resistant to two of the major anti TB drugs, rifampicin (RIF) and isoniazid (INH). ${ }^{7.8}$ FQs function by generating redox ions via Fenton reaction. Oxidation by superoxides produces hydroxyl radicals which in turn oxidize the NADH produced in the TCA cycle by complex electron transport chains thereby forming superoxide ions, which damage the deoxyribonucleic acid (DNA), proteins, and lipids, resulting in cell death. ${ }^{9}$ Slow generation time and thick cell wall cause the slow influx and accumulation of drugs at subinhibitory concentrations.

Proteasomes are the large cylindrical assemblies responsible for controlled protein degradation. The substrate to be degraded is tagged by a specific degradation signal and covalently modified..$^{10-12}$ MTB possesses a prokaryotic ubiquitin-like protein (pup) that targets the protein for degradation, known as pupylation. ${ }^{13,14}$ The pafA gene which forms an operon with pafB and pafC is responsible for tagging the substrate similar to E3 ubiquitin ligase in eukaryotes. ${ }^{15}$ The work of Li et al in 2015 showed that a pafC mutant strain of Mycobacterium smegmatis (MSMEG) was more susceptible to FQs. Other studies have shown that pafBC transcript is involved in the DNA repair mechanism through lexA independent pathway by acting as transcription factor. ${ }^{16,17}$ The study done to characterize the paf operon revealed that though pafA-deficient cells were hypersensitive to RNI, pafBC was required for complete RNI resistance. Complementation with pafA alone was not sufficient to recover the phenotype. ${ }^{15}$ Müller et al have demonstrated the importance of winged helix turn helix of PafC in the regulatory mechanism in DNA stress in Arthrobacter aurescens. Under nonstress conditions the helix turn helix domain is inaccessible for DNA binding..$^{18}$ So far to the best of our knowledge no study has reported the possible mechanism pafC follows to impart resistance to MTB against FQs and most importantly its status in the patients. In our study we aim to characterize the role of pafC gene in response to $\mathrm{FQ}$ and its potential role in $\mathrm{FQ}$ resistance in mycobacteria and intracellular survival.

\section{Materials and Methods}

\section{Type of Study}

A pilot study of 40 subjects was conducted. The patients were selected from the Department of Respiratory Medicine,
KGMU, Uttar Pradesh, Lucknow. Patients presented the symptoms prior to diagnosis, which were cough production, fever, weight loss, hemoptysis, chest pain, loss of appetite, fatigue, and weakness. Ethical approval was granted by Research Cell, KGMU, Uttar Pradesh, Lucknow Institutional Ethics Committee (IEC) [576/Ethics/R.cell-16 dated October 26, 2016].

\section{Inclusion and Exclusion Criteria of Patients}

Inclusion criteria:

- All AFB positive sputum cases.

- Patients who did not respond to first line and second line treatment.

- Prior consent of patients.

Exclusion criteria:

- Human immunodeficiency virus (HIV) positive patients and diabetic patients.

- Patients below 18 years of age and above 60 years of age.

- Patients not giving consent.

- Any form of EPTB.

\section{Sample Collection from TB Patients}

Sputum samples were collected for two consecutive mornings from DOTS registered PTB patients in properly labeled screw cap disposable plastic bottles. Radiological and microscopic analyses along with the drug susceptibility testing were performed to confirm the TB cases.

Each TB patient was provided with an interview form in easy to understand English language. Anonymity and confidentiality of patients were maintained. A 5-mL blood was withdrawn from patients by the trained medical professionals. The sample was collected from susceptible TB patients, MDR-TB patients, and extensively drug resistant (XDR)-TB patients. The blood was immediately transferred to the red topped tubes. It was rested at room temperature (RT) for 1 hour and centrifuged at 3,500 rpm for 15 minutes to remove the clots. The obtained supernatant was the blood sera which were immediately transferred to a new tube and maintained at $4^{\circ} \mathrm{C}$. The sera were further used for immunoblotting.

The serum (at 1:200 dilution) was particularly used to probe the $1 \mu \mathrm{g}$ of purified PafC protein so as to determine its immunogenicity.

The bronchoalveolar lavage (BAL) was collected by trained medical professionals in the bronchology laboratory/operating room. Since it is an invasive technique we could obtain consent from two patients to collect the samples. None of the samples contained blood in them. After collection, the BAL sample was washed three times with incomplete RPMI media, adhered on the 12 well plates, incubated for 24 to 48 hours in complete RPMI media at $37^{\circ} \mathrm{C}$ and $5 \% \mathrm{CO}_{2}$. Post this, adhered cells were scrapped out and lysate was prepared. Unadhered cells were washed off by incomplete RPMI.

\section{In Vitro Cloning of Mycobacterial pafc Gene}

The open reading frame encoding pafC was amplified using flanking anchored primers (HindIII) from MSMEG genomic DNA. TA cloning was performed to clone the polymerase chain reaction (PCR) amplified gene into pTZ57R/T. PCR was 
employed to confirm the positive transformants in Escherichia coli DH5 $\alpha$ competent cells. Plasmids from the positive clones were subcloned into expression vector $p E T 28 b$ (T7 promoter) and integrative shuttle vector pMV361 (hsp60 promoter) at HindIII restriction site. Right orientation of the gene was confirmed via restriction digestion ( - Fig. S1). The orientation of the gene was confirmed by digesting the plasmid from the positive clone by PvuII (in pMV361) and BamHI (in $p E T 28 \mathrm{~b}$ ) restriction enzyme. Both PvuII and BamHI are single cutters in pafC as well as pMV361 and pET28b, respectively. The plasmids from pMV361 positive clones were electroporated in MSMEG to generate the recombinant clones (-Table S1).

The plasmid constructs of pafC in $p E T 28 b$ transformed E. coli Rosetta competent cells to express 6 X His-tagged recombinant proteins induced using isopropyl-D-1-thiogalactopyranoside- $\beta$ (IPTG) at $0.5-\mathrm{mM}$ concentration overnight $(\mathrm{o} / \mathrm{n})$ at $16^{\circ} \mathrm{C}$. The recombinant protein was purified via Ni-NTA chromatography and confirmed by western blotting using rabbit anti-His antibody ( - Fig. S2C). The purified protein was processed for matrix-assisted laser desorption/ionization-mass spectroscopy (MALDI)-TOF MS/MS or mass spectroscopy analysis which confirmed it to be PafC protein according to the NCBI (National Center for Biotechnology Information) database ( - Fig. S2D). A detailed list of primers and chemicals used in the study is provided in the - Tables $\mathbf{S} \mathbf{2}$ and $\mathbf{S 3}$.

\section{Production of Polyclonal Antisera against PafC}

$200 \mu \mathrm{g}$ of purified PafC was injected subcutaneously with Freund's incomplete adjuvant in female adult white New Zealand rabbit. Immunization was performed on days 0 and then two booster doses on day 15 and day 30 . On day 45 , rabbit was bled intracardially and the serum was separated by incubating at $37^{\circ} \mathrm{C}$ for 2 hours before transferring to $4^{\circ} \mathrm{C}$. Coagulated blood was then centrifuged in cold at 2,000 $\times \mathrm{g}$ for 10 minutes; serum was collected and aliquoted in $250-\mu \mathrm{L}$ fractions and stored at $-80^{\circ} \mathrm{C}$ for further use. The anti-PafC antiserum was confirmed for its reactivity with PafC protein via western blotting. Primary PafC antibody at 1:500 dilution was checked for its specificity at different concentrations of purified protein (-Fig. S6).

\section{Protein Estimation and Western Blot Analysis}

The protein estimation was done by Bradford assay. The bovine serum albumin was diluted in triple distilled water from concentrations 0.5 to $5 \mu \mathrm{g}$ in a 96-well plate (total $100 \mu \mathrm{L}$ volume). Bradford reagent (Coomassie blue dye) was then added at 1:1 ratio and reading was taken at $595 \mathrm{~nm}$ in a spectrophotometer. The data obtained was used to plot the standard graph with absorbance on the $y$-axis and the known protein concentration on the $x$-axis. Absorbance $(y)$ of the standard was calculated using the formula $y=m x+c . R^{2}$ was maintained at least at 0.98 . For estimating the protein concentration of the unknown sample its absorbance was plotted on the standard graph and calculated by using the formula [(absorbance of the test sample)/(absorbance of the standard sample)] $\times$ dilution factor of the test sample. New standard graph was plotted for a fresh experiment.
Proteins separated by SDS-PAGE were transferred to PVDF membrane which was charged by soaking in methanol and then equilibrated by dipping in transfer buffer. Polyacrylamide gel and PVDF membrane were sandwiched between sheets of Whatman-3 blotting paper, preabsorbed in transfer buffer. This gel-membrane cassette was placed in the semidry transfer unit. The proteins were transferred at $200 \mathrm{~mA}$ for 60 minutes. After transfer, the membrane was then blocked with $5 \%$ blotto in TBST buffer (20 mM Tris-Cl, $50 \mathrm{mM} \mathrm{NaCl}$, and $0.5 \%$ Tween 20) for 2 hours. Appropriate dilutions of primary antibodies were prepared in $2.5 \%$ blocking buffer and the gel was soaked in it for 12 to 16 hours at $4^{\circ} \mathrm{C}$ with mild shaking. The membrane was then washed three times with TBST buffer. After washing away the unbound primary antibody, the membrane was incubated with the appropriate secondary antibody (IgG-HRP) in $2.5 \%$ blocking buffer for 1 hour at RT. The membrane was washed three times with TBST and detection was performed with the Enhanced Chemiluminescence reagent. The blots were analyzed on LAS 500 gel-doc system using Image quant analysis software.

\section{Growth Kinetics of MSMEG}

Recombinant MSMEG cultures were grown to mid-log phase $\left(\mathrm{OD}_{600}=0.4-0.6\right)$ in LBGT media and then diluted to the $\mathrm{OD}_{600}$ of 0.02 . The cultures were allowed to grow at $37^{\circ} \mathrm{C}$ at $180 \mathrm{rpm}$ in a shaker incubator and the absorbance was measured at different time intervals $(0,4,8,12,24,48,72$, 96, and 118 hours). At every time interval the cultures were also plated on LBGTA medium for colony forming unit (CFU) counts. Three drops of $10 \mu \mathrm{L}$ each were placed on the media. To obtain the countable number of colonies, especially at higher time points wherein the bacterial growth increased, each culture was diluted and simultaneously plated at different dilutions. MS_VEC was the control for all experiments with recombinant MSMEG cultures. Cell line, bacterial strains, plasmids, and growth conditions are given in detail in supplementary file.

\section{Intracellular Survival of Mycobacteria and Drug Efficacy}

J774A.1 murine macrophage cell line was meant to study the intracellular behavior of MSMEG. The cells were seeded at a density of $2 \times 10^{5}$ cells/well in 12 well tissue culture plates and infected with log phase recombinant mycobacterial cultures at 1:10 MOI. Cells were replenished with complete medium containing $100 \mu \mathrm{g} / \mathrm{mL}$ amikacin to kill any extracellular bacteria and prevent secondary infection. To estimate the intracellular survival of MSMEG, the cells were lysed and plated for CFU count on LBGTA medium.

For studying the effect of individual anti TB drugs in intracellular mycobacteria, after 3 hours of infection, the intracellular mycobacteria were treated with levofloxacin (LFX), ofloxacin (OFX), and moxifloxacin (MFX) at different concentrations $(8,4,2,1$, and $0.5 \mu \mathrm{g})$ for 2 hours. The infected J774A.1 cells were washed with incomplete RPMI media before they were treated with drugs. Post drug treatment, the macrophages were lysed and plated on solid 
media without any antibiotic for CFU counting. Uninfected cells and infected cells without drug treatment were the controls.

\section{Effect of Stress on PafC Expression}

The log phase recombinant mycobacterial cultures were grown in Sauton's media (minimal media) to understand the behavior of PafC under different stress conditions: $\mathrm{pH} 4.5,5.5$; NO stress; $\mathrm{H}_{2} \mathrm{O}_{2}$ stress; nutrient stress and hypoxia. $\mathrm{pH}$ of the media was adjusted to acidic levels by $5 \mathrm{~N} \mathrm{HCl}$; deta NO was used to give $\mathrm{NO}$ stress and hydrogen peroxide for $\mathrm{H}_{2} \mathrm{O}_{2}$ stress. To create nutrient stress the cultures were grown in $1 \times$ PBS. The hypoxic condition was created by filling the culture to the brim of the culture tube and sealing it completely with paraffin. Methylene blue was added as hypoxia indicator. Upon attaining the hypoxic environment blue color of the dye changes to white. The culture at $\mathrm{pH} 7.2$ was the control. The cultures were subjected to respective stress for three cycles, after which the cultures were pelleted down, and the obtained pellet was processed for western analysis.

\section{Antimycobacterial Activity of the Fluoroquinolones}

REMA is based on the reduction of the nonfluorescent dye resazurin (blue) to fluorescent resorufin (pink) by living cells and was used to detect antimycobacterial activity of compounds. For calculating the minimum inhibitory concentration (MIC) ${ }_{50}$ of drugs, mid-log phase cultures of MSMEG were incubated at different drug concentrations $(100-0.012 \mu \mathrm{g})$ in 96 well plates for three cycles at $37^{\circ} \mathrm{C}$. Following incubation, $0.02 \%$ resazurin was added into each well at $10 \%$ of total volume and further incubated at $37^{\circ} \mathrm{C}$ till the color developed. The highest concentration of DMSO did not exceed $0.1 \%$. Relative to cellular viability, upon aerobic respiration by metabolically active cells the resazurin (purple) was irreversibly reduced to resorufin (pink). Subsequent fluorescence was recorded at 530/590 $\mathrm{nm}$ wavelengths (570 $\mathrm{nm}$ cut off).

\section{Measurement of Fluoroquinolone Accumulation}

As described earlier, ${ }^{19}$ the FQ accumulation was measured in mycobacterial cultures with some modifications. Mid-log phase cultures were harvested via centrifugation at 3,000 $\times \mathrm{g}$ for 20 minutes at $15^{\circ} \mathrm{C}$. Cells were washed with $50-\mathrm{mM}$ sodium phosphate buffer (pH7) and concentrated with same buffer. The obtained bacterial suspension was placed in a stirring water bath at $37^{\circ} \mathrm{C}$ for 10 minutes. LFX, OFX, and MFX were added to a final concentration of $10 \mu \mathrm{g} / \mathrm{mL}$ and $1-\mathrm{mL}$ sample from each was removed at timed intervals. Samples were immediately centrifuged, and the pellets were washed with sodium phosphate buffer, resuspended in $1 \mathrm{~mL}$ of $0.1 \mathrm{M}$ glycine- $\mathrm{HCl}(\mathrm{pH} 3)$ and left $\mathrm{O} / \mathrm{N}$ at RT with agitation to lyse. Next day the samples were centrifuged at $12,000 \times g$ and the fluorescence of supernatants was determined at $281 / 440-n m$ wavelengths.

\section{Effect of Fluoroquinolones on Mycobacteria and Quantitative RT-PCR}

The behavior of pafC and two DNA damage repair enzymes (lexA and recA) was studied in the presence of FQs by mRNA expression analysis. The cultures of MSMEG and MTB were treated with LFX, OFX, and MFX at their respective MICs for 1 hour. After drug treatment the RNA was isolated and single strand CDNA synthesis was performed.

The mycobacterial cultures were centrifuged, and the pellet was suspended in $100 \mu \mathrm{L}$ of lysozyme of concentration $50 \mathrm{mg} / \mathrm{mL}$ with $900 \mu \mathrm{L}$ of $1 \times$ PBS (in DEPC water) added to the mixture. The suspension was vortexed for 10 seconds and left at RT for 15 minutes followed by centrifugation. The pellet thus obtained was suspended in $500 \mu \mathrm{L}$ of RLT buffer provided in the Qiagen kit and the RNA was isolated as per the manufacturer's protocol.

Approximately $10 \mu \mathrm{g}$ of total RNA was treated with 2 to 4 units of RNase free DNase (Thermo Scientific) in $1 \times$ DNase buffer for 30 minutes at $37^{\circ} \mathrm{C}$. The reaction was terminated by heating at $65^{\circ} \mathrm{C}$ for 10 minutes for inactivation of DNase. $1 \mu \mathrm{g}$ of RNA was reverse transcribed using RevertAid H Minus Reverse Transcriptase. Random hexamer primers were used for the cDNA synthesis. The reaction was started by incubating the reaction mix at $25^{\circ} \mathrm{C}$ for 10 minutes which was followed by 60 minutes incubation at $42^{\circ} \mathrm{C}$. The reaction was terminated by inactivating reverse transcriptase at $70^{\circ} \mathrm{C}$ for 10 minutes. Quantitative real time PCR ( $q R T-P C R$ ) was performed in 96 well plate on Applied Biosystems StepOne Real-Time PCR Systems using Power SYBRGreen PCR Master Mix (Thermo Scientific) with 10 pmoles of gene-specific primers. Intracellular bacteria in J774.A1 cell line (at 1:10 MOI) and the bacteria cultured from patient samples were also processed the same way. The calculated cycle threshold $(\mathrm{Ct})$ of the test gene was normalized to the $\mathrm{Ct}$ of the internal control (16S) gene. Similarly, the calculated delta $\mathrm{Ct}$ of treated samples was normalized with the calculated delta $\mathrm{Ct}$ of untreated samples (UN). The obtained delta Ct was then used to estimate the fold change.

\section{Preparation of Culture Filtrates}

To prepare the culture filtrate, recombinant cultures of MSMEG were grown to mid-log phase, pelleted down at 2,000 $\times g$ for 10 minutes at RT. The obtained pellets were washed twice with sterile $1 \times$ PBS and suspended in Sauton's medium to grow for three cycles. Further the cultures were pelleted by centrifugation at $2,000 \times g$ for 10 minutes. The supernatant was again centrifuged at $2,000 \times g$ for 10 minutes in cold. The resulting supernatant generated was filtered twice, once with $0.45 \mu \mathrm{m}$ filter and next with $0.22 \mu \mathrm{m}$ filter. The obtained filtrate was TCA precipitated (added at $15 \%$ of the volume of the filtrate) at $20^{\circ} \mathrm{C}$ for 16 hours. The precipitate was then washed with acetone thrice and air dried. The obtained pellet was suspended in rehydration buffer and subjected to western blot analysis.

\section{Statistical Analysis}

GraphPad Prism 5.03 software was used to plot graphs. The p-value of $<0.05$ was considered to be statistically significant. The statistical significance was defined by one-way ANOVA. All experiments were conducted in triplicate. 


\section{Results}

\section{Patients' Profile}

The study was performed on selected 40 PTB cases. The demographic profiles and other details of selected 40 PTB patients are summarized in - Table $\mathbf{1}$. There was no particular demarcation in the patients from urban or rural setting, but the number of males was significantly higher than females. Maximum patients with TB either had a family history of the disease or were in close contact with a TB patient. These patients were divided into three groups, susceptible TB 11 (27.5\%), 20 (50.0\%) MDR patients, and rest 09 (22.5\%) patients were XDR (- Table 1). Among 40 cases, 24 were males and remaining 16 were females (60.0 and $40.0 \%$ ). All of them were in the age group of 18 to 60 years. Of the 40 cases, $30(75.0 \%)$ were in low income group and only 10 (25.0\%) from middle-income group. DR patients in our study either had history of inadequate treatment or were in close contact with TB patients. The number of male patients were more than the female patients.

\section{Cloning of pafC and Generation of Recombinant Strains of MSMEG}

The open reading frame encoding pafC when amplified from MSMEG genomic DNA gave a 957-bp fragment, as also when amplified in pET28b and pMV361 (Fig. S2B). As observed through SDS-PAGE of culture lysates, IPTG-induced protein was found to be approximately $40 \mathrm{kDa}$ in size. $10 \mu \mathrm{L}$ of each lysate was run on the gel (Fig. S2C). The $40 \mathrm{kDa}$ size of PafC was due to the $6 \times$ His tag added to the native $33 \mathrm{kDa}$ PafC protein. The induced PafC protein which was purified via Ni-NTA affinity chromatography was eluted in three different concentrations of imidazole $(150,300$, and $450 \mathrm{mM})$. Amongst these, the best elution was obtained at $300-\mathrm{mM}$ imidazole concentration (Fig. S2C). Presence of a single prominent band on SDS-PAGE confirmed the homogeneity of the protein. The pMV361 vector containing sense and antisense clone of pafC weas electroporated into MSMEG to generate namely MS_OE, MSMEG containing pMV361:pafC overexpressing PafC under hsp60 promoter; MS_KD, MSMEG containing pMV361:pafC under-expressing PafC under hsp60 promoter. MS_VEC, MSMEG containing pMV361 alone was the control. The OE and KD clones were confirmed by western blot analysis.

\section{PafC Enhances the Intracellular Survival of MSMEG}

Growth and intracellular survival form the basis for any intracellular pathogen to successfully cause an infection. Mycobacteria have been an exceedingly successful human pathogen and therefore we studied if pafC plays any part in its growth, survival and thereby have a role in establishing an infection. The initial bacterial load was kept equal in all such experiments so as to nullify any discrepancy in data. Growth curve plot analysis showed no significant difference in the growth pattern of different strains of MSMEG ( - Fig. 1A). Upon studying the intracellular survivability of mycobacteria in J774A.1 macrophage cell line, it was observed that at
Table 1 Demographic profile of patients

\begin{tabular}{|c|c|c|c|}
\hline \multicolumn{4}{|c|}{ Demographic profile of patients } \\
\hline $\begin{array}{l}\text { S. } \\
\text { No }\end{array}$ & Variables & $\begin{array}{l}\text { No. of } \\
\text { samples } \\
(n=40)\end{array}$ & Percentage\% \\
\hline 1 & \multicolumn{3}{|c|}{ Residence } \\
\hline & Urban & 18 & 45.0 \\
\hline & Rural & 22 & 55.0 \\
\hline 2 & \multicolumn{3}{|c|}{ Gender } \\
\hline & Male & 24 & 60.0 \\
\hline & Female & 16 & 40.0 \\
\hline 3 & \multicolumn{3}{|c|}{ Age } \\
\hline & $18-30$ & 28 & 70.0 \\
\hline & $31-40$ & 06 & 15.0 \\
\hline & $41-50$ & 02 & 5.0 \\
\hline & $51-60$ & 04 & 10.0 \\
\hline 4 & $\begin{array}{l}\text { Living pattern } \\
\text { - Pucca house } \\
\text { - Kachha house }\end{array}$ & $\begin{array}{l}10 \\
30\end{array}$ & $\begin{array}{l}25.0 \\
75.0\end{array}$ \\
\hline 5 & $\begin{array}{l}\text { Ventilation } \\
\text { - Dampness } \\
\text { - Light }\end{array}$ & $\begin{array}{l}17 \\
23\end{array}$ & $\begin{array}{l}42.5 \\
57.5\end{array}$ \\
\hline 6 & $\begin{array}{l}\text { Smoking history } \\
\text { - Smoker } \\
\text { - Non-smoker } \\
\text { - Ex-smoker }\end{array}$ & $\begin{array}{l}21 \\
06 \\
13\end{array}$ & $\begin{array}{l}52.5 \\
15.0 \\
32.5\end{array}$ \\
\hline 7 & $\begin{array}{l}\text { Types of smoking } \\
\text { - Cigarette } \\
\text { - Bidi } \\
\text { - Hukka } \\
\text { - Chillum } \\
\text { - Biomass fuel }\end{array}$ & $\begin{array}{l}16 \\
12 \\
02 \\
04 \\
06\end{array}$ & $\begin{array}{l}40.0 \\
30.0 \\
05.0 \\
10.0 \\
15.0\end{array}$ \\
\hline 8 & $\begin{array}{l}\text { History of other addiction } \\
\text { - Alcohol } \\
\text { - Narcotics }\end{array}$ & $\begin{array}{l}24 \\
16\end{array}$ & $\begin{array}{l}60.0 \\
40.0\end{array}$ \\
\hline 9 & $\begin{array}{l}\text { Family history of TB } \\
\text { - Yes } \\
\text { - No } \\
\text { - Not known } \\
\text { - Contact with TB patients }\end{array}$ & $\begin{array}{l}19 \\
04 \\
06 \\
11\end{array}$ & $\begin{array}{l}47.5 \\
10.0 \\
15.0 \\
27.5\end{array}$ \\
\hline 10 & $\begin{array}{l}\text { Past history of pulmonary TB } \\
\text { - Yes } \\
\text { - No }\end{array}$ & $\begin{array}{l}28 \\
12\end{array}$ & $\begin{array}{l}70.0 \\
30.0\end{array}$ \\
\hline 11 & HIV status & $\begin{array}{l}\text { All } \\
\text { negative }\end{array}$ & $100 \%$ \\
\hline 12 & Diabetes mellitus & $\begin{array}{l}\text { All } \\
\text { negative }\end{array}$ & $100 \%$ \\
\hline 13 & $\begin{array}{l}\text { Patients category } \\
\text { - } \text { Primary TB } \\
\text { - } \text { MDR cases } \\
\text { - XDR cases }\end{array}$ & $\begin{array}{l}11 \\
20 \\
09\end{array}$ & $\begin{array}{l}27.5 \\
50.0 \\
22.5\end{array}$ \\
\hline
\end{tabular}

Abbreviations: MDR, multidrug-resistant; TB, tuberculosis; XDR, extensively drug resistant. 

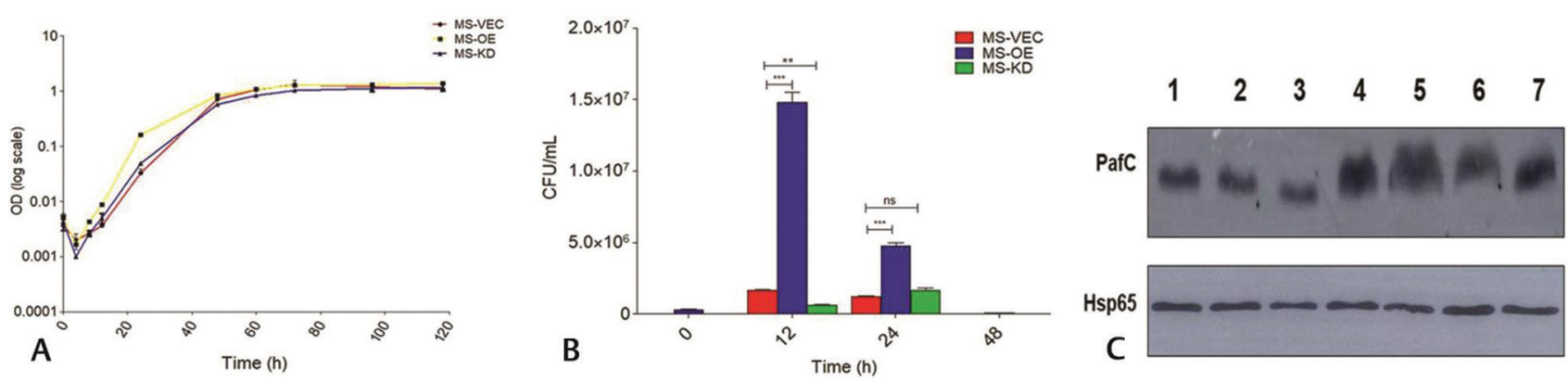

Fig. 1 Growth kinetics and intracellular survival. (A) Growth curve assay of recombinant MSMEG strains was plotted at log ${ }_{10}$ against MS_VEC from time points 0 to 118 hours. No significant difference in growth was observed. $p<0.05$. (B) Intracellular survival assay in J774A.1 macrophage cell line. The MS_OE showing increased survival at 12 and 24 hours. Uninfected cells did not give any growth on agar medium. (C) Expression of PafC under stress. Lane1, pH 7.2 as control; Lane 2, pH 4.5; Lane 3, pH 5.5; Lane 4, $\mathrm{H}_{2} \mathrm{O}_{2}$ at 10 mM; Lane 5, NO- at 0.5 mM; Lane 6, Hypoxia; Lane 7, 1X PBS. Hsp65 was the loading control. MSMEG, Mycobacterium smegmatis; PafC, proteasome accessory factor- $\mathrm{C}$.

12 hours and 24 hours MS_OE had significantly increased intracellular survival in comparison with MS-KD and MS VEC ( - Fig. 1B). Another important finding was approximately nine times increased phagocytosis of MS_OE strain at 0 hours ( - Fig. S3). Increased survival of PafC overexpression strain (MS_OE) in J774A.1 macrophage cell line underlined PafC's role in allowing the bacteria to exist inside the host macrophages ( - Fig. S4).

\section{Upregulation of PafC during Stress}

When inside a granuloma, mycobacteria encounter different kinds of stresses like nutrient deprivation, oxidative stress, etc. The bacteria overcome such harsh conditions to establish a successful infection inside the host. Lysates of MSMEG $(20 \mu \mathrm{g})$ culture subjected to various stresses were run on the gel and immunoblotted with PafC primary antibody at 1:40,000 dilution. The protein expression analysis of PafC in MSMEG subjected to stress akin to that encountered inside host showed elevated PafC expression during $\mathrm{H}_{2} \mathrm{O}_{2}$ stress, NO-stress, and nutrient deprivation ( - Fig. 1C). This upregulation of PafC indicates that it directly or indirectly, helps mycobacteria persist under stress inside granuloma and also survive the presence of drugs that have oxidative/nitrosative stress as their bactericidal mode of action.

\section{Minimum Inhibitory Concentration $\left(\mathrm{MIC}_{50}\right.$ ) and Intracellular Efficacy of Drugs}

Since FQs kill mycobacteria by generating oxidative stress and we have already established that PafC has increased expression under oxidative/nitrosative stress; we instigated the $\mathrm{MIC}_{50}$ of FQs for recombinant MSMEG strains. The resazurin dye assay showed that MS_OE has increased $\mathrm{MIC}_{50}$ (-Fig. 2A) meaning that FQs in a PafC overexpression strain were not as effective as they were in other two strains (MS_VEC and MS_KD). Further deciphering the role of PafC in relation to drugs, when the intracellular recombinant MSMEGs were treated with FQs at different concentrations, MS_KD showed an escalated growth ( - Fig. 2B-D). The range of drug concentrations used in the experiment was decided considering the MICs of all three FQs against
MSMEG which also covered the $\mathrm{MIC}_{50}$ of our recombinant strains. The decreased growth in MS_OE could have been due to the stalling of growth pertaining to the metabolic shutdown in the presence of drugs. But the hypothesis still required a valid confirmation and therefore the accumulation of FQs was studied. No morphological changes were observed due to antibiotic stress ( - Fig. S5).

\section{Reduced FQ Accumulation in Mycobacteria Overexpressing PafC}

When subjected to stress either drug generated or host's immune system generated, the mycobacteria could acquire a state of latency wherein it becomes metabolically inactive. Owing to the reduced growth of intracellular MS_OE in the presence of FQs, we wanted to check the status of FQs inside the mycobacteria and hence the accumulation of FQs was studied in recombinant MSMEG strains and MTB H37Ra. The fluorometric analysis showed significantly lower drug accumulation in MS_OE than MS_KD ( - Fig. 3). It delineated the attribute that PafC does indeed counter the FQ accumulation via increased efflux. With the results obtained here it could be established that increased drug efflux in the PafC overexpression strain shifted mycobacteria toward a state of metabolic dormancy which lead to its decreased growth inside macrophages. The slow growing WT H37Ra showed a gradual increase in drug accumulation over the period of time due its more rigid cell wall composition than MSMEG, but the accumulation was still higher than MS_OE (-Fig. $\mathbf{3}$ ).

\section{PafC is Nonsecretory}

Many pathogenic mycobacterial proteins like ESAT-6 and CFP-10 are secretory in nature. Since proteasomes provide mycobacteria its pathogenicity and paf operon works in association with them, we investigated if this feature was controlled by its secretion.

Prior to proceeding for the detection in culture filtrates, specificity of PafC Ab was checked against purified protein as well as bacterial lysates (- Figs. S2E and S6). Antisera against PafC were generated using purified proteins by immunization in rabbit described in methods section. The antisera were confirmed for their reactivity with target protein using western 


\begin{tabular}{|c|c|c|c|}
\hline \multirow{2}{*}{ Drugs } & \multicolumn{3}{|c|}{ MIC $_{\text {50 }}$} \\
\cline { 2 - 4 } & MS-361 & MS-OE & MS-KD \\
\hline Levofloxacin & $\geq 0.39$ & $\geq 1.56$ & $\geq 0.098$ \\
\hline Ofloxacin & $\geq 1.56$ & $\geq 3.125$ & $\geq 1.56$ \\
\hline Aoxifloxacin & $\geq 0.19$ & $\geq 0.39$ & $\geq 0.098$ \\
\hline
\end{tabular}
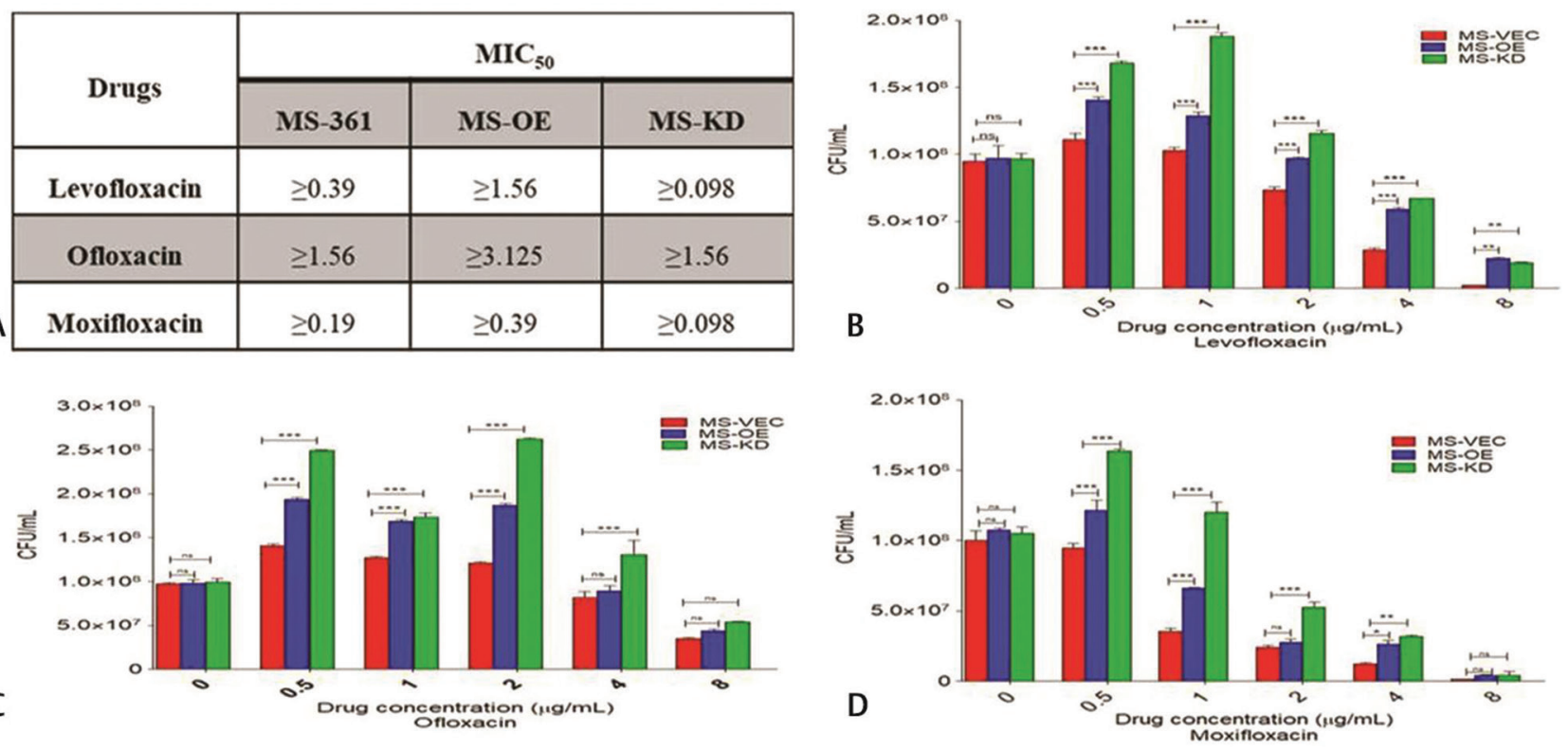

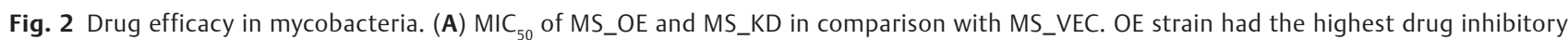
concentration of all. (B-D) Intracellular drug efficacies against recombinant MSMEG and MS_VEC at different drug concentrations. MS_OE had lower survival than MS_KD. MSMEG, Mycobacterium smegmatis.
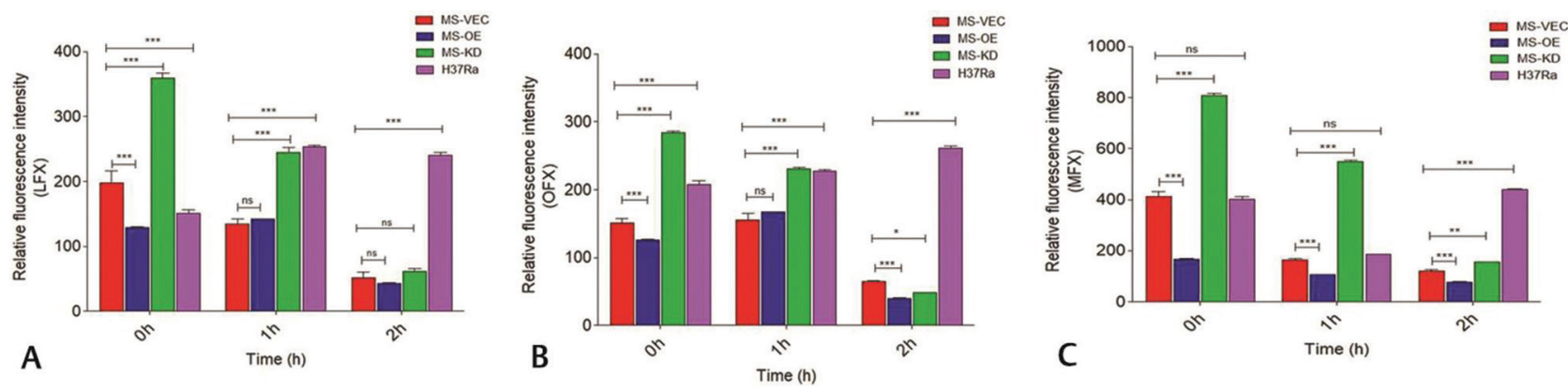

Fig. 3 Fluoroquinolone accumulation in mycobacteria (A) Levofloxacin (B) ofloxacin, and (C) moxifloxacin. A lower accumulation of fluoroquinolones was observed in MS_OE.

blotting and were also used for detection of protein expression in mycobacteria. Purified PafC was run at different concentrations (5 ng to $2 \mu \mathrm{g}$ ) and its specificity against PafC primary antibody was done by western blot analysis. Similarly PafC was confirmed to be present in MSMEG upon probing the lysate with PafC primary antibody. Best results with bacterial lysates were obtained at 1:40,000 PafC primary antibody dilution.

The $100 \mu \mathrm{g}$ of culture filtrates of recombinant MSMEG strains were probed with PafC antibody (at 1:500 dilution) but none showed the presence of PafC protein. Corroborating to it when 1- $\mu$ g PafC purified protein was immunoblotted with sera from different TB patients (susceptible, MDR, and XDR) at 1:500 dilution it went undetected in them either. Absence of PafC in the culture filtrates and patient sera confirmed its nonsecretory nature ( - Fig. 4A, B). Antigenic nature of PafC was determined when it was detected in the BAL of TB patients through western blot analysis ( - Fig. 4C). A $100 \mu \mathrm{g}$ of lysate prepared from BAL of TB patients (as described in methods section) was when probed with PafC primary antibody at 1:1,000 dilution, a prominent band $33 \mathrm{kDa}$ was detected on the blot.

\section{Clinical Significance of Upregulated pafC mRNA Expression upon FQ Treatment}

Extending on the antigenicity of PafC, when pafC expression was studied upon treating bacteria with FQs in culture and intracellularly, it showed higher mRNA expression in the presence of FQs than RIF ( - Fig. 4D, E).

Comparison of pafC mRNA expression amongst drug susceptible, MDR and XDR patients revealed the upregulation of pafC mRNA in DR cases than drug susceptible cases, though XDR patients had lower expression than MDR patients (-Fig. 4F). The drug susceptible patients which were not treated with FQs had the lowest pafC mRNA level of all and the XDR patients which were resistant to FQs had pafC mRNA higher than susceptible patients but lower than MDR patients. Through qRT-PCR analysis we proved the connection between FQs and PafC and also that PafC is involved in providing mycobacteria resistance against FQs. The clinical data were in line with results obtained with mycobacteria in culture as well as the intracellular mycobacteria. 
A

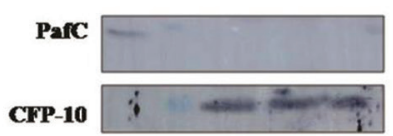

B

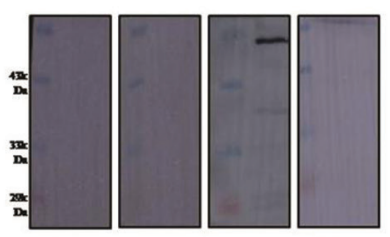

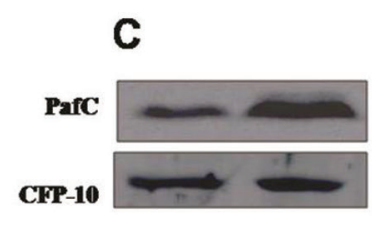

E

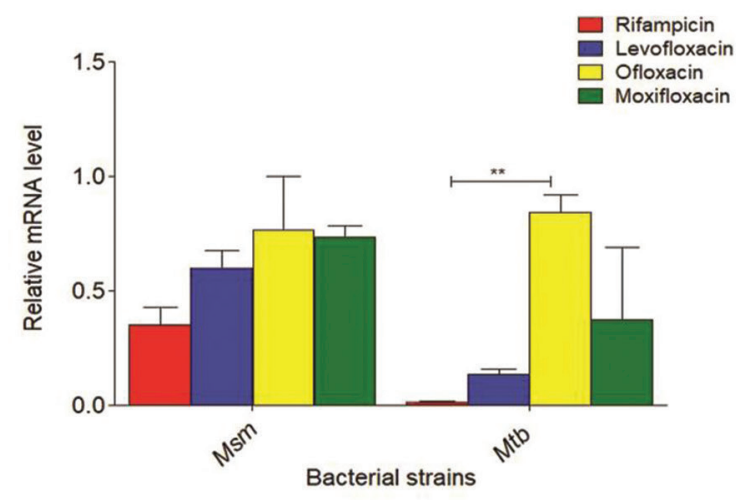

D

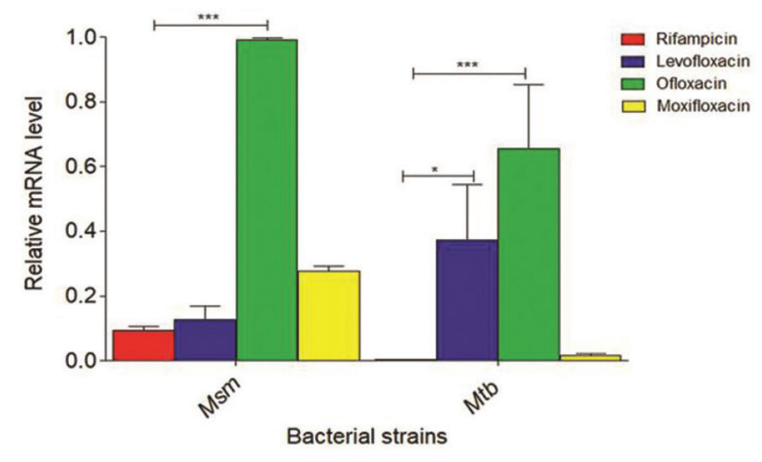

$\mathbf{F}$

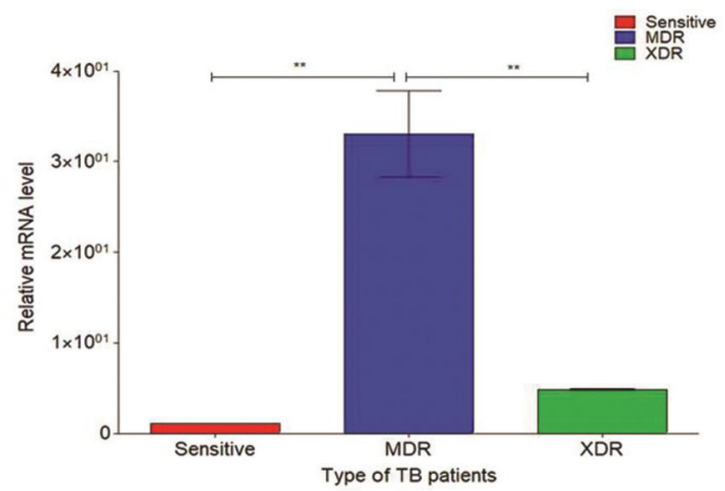

Fig. 4 Antigenicity and upregulation of PafC. (A) Detection of PafC in culture filtrates. Lane 1 purified PafC protein; Lane 2, protein ladder; Lane 3, MS_VEC; Lane 4, MS_OE; Lane 5, MS_KD. CFP-10 was the control. (B) Detection of PafC inpatient sera. Lane 1, healthy volunteer sera; Lane 2, susceptible patient sera; Lane 3, MDR patient sera; Lane 4, XDR patient sera. (C) Detection of PafC in BAL samples obtained from TB patients (Lanes 1 and 2 show samples from two different patients). CFP-10 was used as control. (A) and (B) show the nonsecretory nature of PafC whereas (C) shows its antigenic nature. (D) pafC mRNA expression level in MSMEG and MTB in culture on drug treatment. (E) pafC mRNA expression level in intracellular MSMEG and MTB on drug treatment. (F) mRNA expression level in bacteria from TB patients. (D) to (F) demarcate the upregulation of pafC in the presence of FQs. The expression levels were considerably higher than when treated with first line drug. BAL, bronchoalveolar lavage; MDR, multidrug-resistant; MSMEG, Mycobacterium smegmatis; MTB, Mycobacterium tuberculosis; PafC, proteasome accessory factor-C; TB, tuberculosis; XDR, extensively drug resistant.

\section{Regulation of DNA Repair Enzymes by PafC}

It is well known that FQs induce DNA damage that is bactericidal. Hence it became necessary to check the involvement of PafC in DNA damage in mycobacteria. For this, two enzymes lexA and recA were taken up. Normally lexA is present in higher quantity that recA as it inhibits the transcription of recA. Upon DNA damage, the autolysis of lexA leads to the transcription of recA which in turn upregulates the transcription of SOS DNA damage repair enzymes.

MSMEG recombinant strains were treated with FQs at their respective MICs and the qRT-PCR analysis of lexA and recA mRNA transcripts showed their increased expression in MS_OE. RIF was the control drug ( - Fig. 5A, B). Same expression pattern was observed in PTB patients as well, wherein the DR patients had significantly higher expression of lexA and recA in comparison with drug-susceptible patients ( - Fig. 5C, D). In both, recombinant MSMEG and patient samples around 5 to 10 folds difference was observed between the mRNA expression levels of recA and lexA in the presence of FQs. The result corroborated with expression profile of pafC in MDR and XDR patients, i.e., they gave higher mRNA expression in MDR patients than in XDR patients. Here we conclude that pafC have a definite role in protecting mycobacteria against the damaging effects of the FQs by increasing DNA damage response.

\section{Discussion}

MTB has evolved over centuries to modulate the host's defense mechanism for its own survival. The bacteria possess the ability to persist inside the granuloma for an extended period of time sometimes even for the lifetime of an individual, without causing an active disease. Both extrinsic and intrinsic mechanisms help bacteria in its survival inside host and also acquire drug resistance against antituberculosis therapy (ATT). There are more than one factors involved which help mycobacteria in surviving inside granuloma's unfavorable environment. ${ }^{6,20-22}$ MTB boasts of highly efficient 

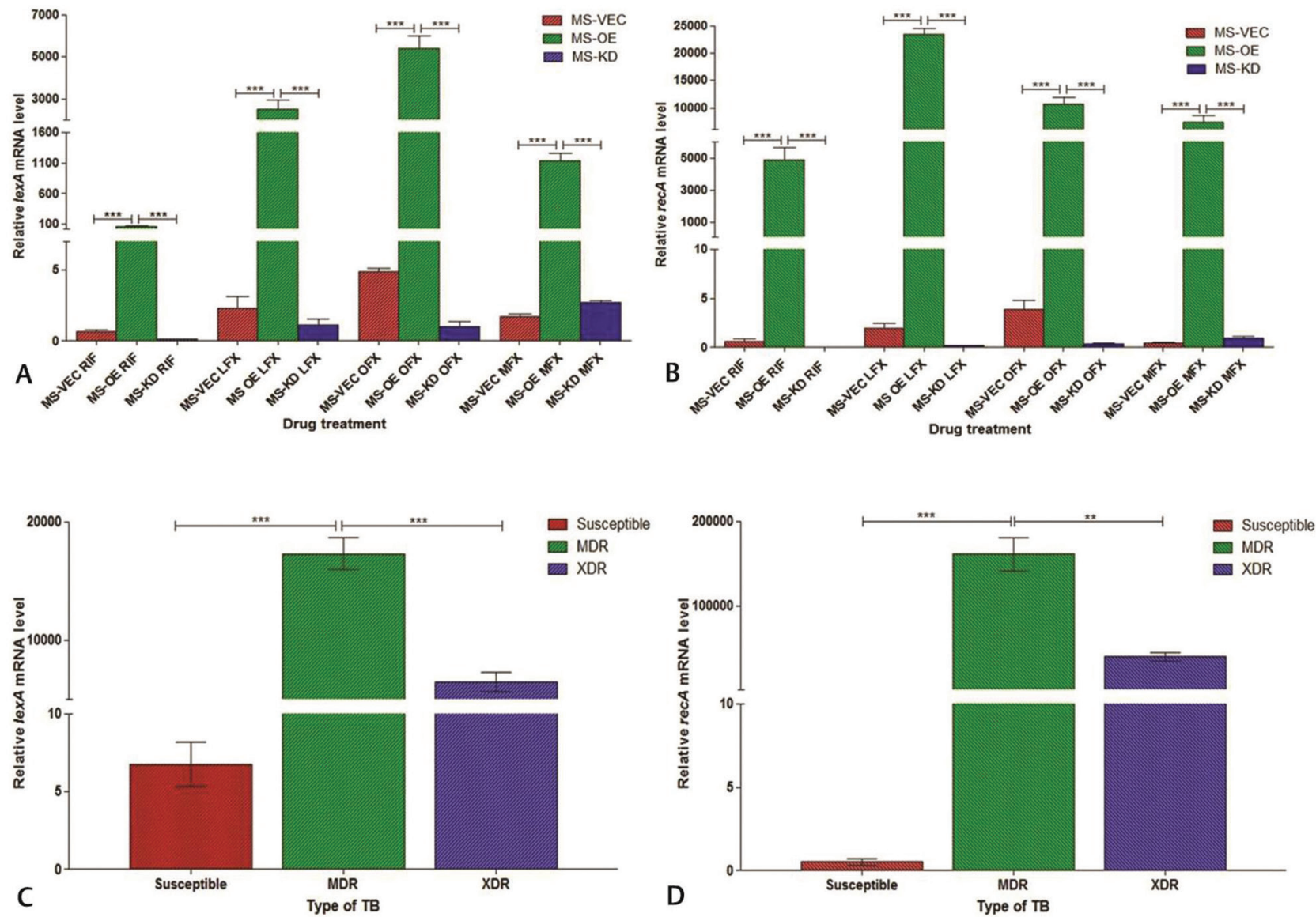

Fig. 5 Increased expression of DNA repair enzymes. (A, B) Recombinant MSMEG strains were treated with RIF, LFX, OFX, and MFX at their respective MIC and the lexA and recA mRNA expression was quantified, respectively. MS_OE had increased lexA and recA mRNA expression in comparison with MS_VEC and MS_KD. (C, D) mRNA expression analysis in pulmonary TB patients showed higher expression of lexA and recA in DR patients, specifically in MDR patients as compared with susceptible patients. DNA, deoxyribonucleic acid; LFX, levofloxacin; MDR, multidrug resistant; MFX, moxifloxacin; MSMEG, Mycobacterium smegmatis; MTB, Mycobacterium tuberculosis; OFX, ofloxacin; RIF, rifampicin; TB, tuberculosis; XDR, extensively drug resistant.

approach that provides it the ability to overcome the adverse effects of drugs. Prolonged exposure to drugs, ability to modify antigenic markers, thick cell wall, fewer porins, and drug efflux pumps are the major determinants of drug resistance in mycobacteria. ${ }^{23-25}$ In the recent years there has been an upsurge in the drug resistant TB cases. Patients with MDR are difficult to treat as the time taken to completely cure it could take up to 2 years and simultaneously being exposed to high concentrations of drug for such long periods has its own repercussion on the patients. Hence there is a dire need to identify new markers/drug targets which could help in combating the drug resistance in $\mathrm{TB}$ and make its diagnosis an easy task. FQs, the drugs used to treat MDR-TB, function by generating oxidative stress that obstructs the functioning of DNA thus, ultimately killing the bacteria. ${ }^{7.26}$

Similar to eukaryotes, MTB possesses proteasome degradation machinery, known as pup proteasome system. It targets the proteins intended for degradation. paf operon forms an essential part of this system. pafA gene of this operon has been well characterized to tag the protein destined for degradation by proteasome machinery. It works in a fashion similar to E3 ubiquitin ligase in eukaryotes. Other two genes pafB and pafC have not been that well characterized. Keeping this in consideration, an extensive literature search directed us toward pafC gene, which has a possible function in FQ resistance in mycobacteria. ${ }^{27}$ But the possible mechanism of its involvement and how does it operate remained to be elucidated.

We started out by characterizing the pafC gene in fast growing and slow growing mycobacteria through bioinformatics analysis. The protein sequences obtained from Mycobrowser were subjected to amino acid sequence analysis via ESPript. Presence of consensus sequence between the two, suggested an evolutionary importance of PafC ( - Fig. S2A). This is supported by the fact that proteasome complex is responsible for mycobacterium's pathogenicity and $M$. leprae has maintained complete paf operon despite its shorter genome size. ${ }^{15,28}$ MSMEG differs from MTB in physiological requirement and ecological requirements, but it has a pup-proteasome similar to it and unlike in other mycobacterial species, $p a f B$ and pafC are present adjacent to pafA in both. 
For example, in Mycobacterium abscessus, Mycobacterium rutilum and Nocardia pafB and pafC are separated from pafA.

The primary objective of any pathogen is to successfully establish an infection inside its host; hence, we first studied the role of PafC in mycobacterial growth and intracellular survival. Two recombinant strains of PafC, OE and KD, were generated to study its functioning in the presence of FQs. Increased intracellular survival and phagocytosis of MS_OE manifests that PafC is allowing mycobacteria to get successfully internalized and establish an infection (-Figs. 1B and S3). To contain the MTB infection, RNI and ROS are two of the major defense mechanisms employed by host's immune system. It is also the mode of action of FQs. Due to their moderate in vivo activity FQs are given as the second line treatment in TB. The microenvironment inside the granuloma is there to primarily contain the bacteria, but it also provides bacteria the niche to survive quite efficiently. ${ }^{3}$ Mycobacteria bypasses oxidative stress, nutrient starvation, and low $\mathrm{pH}$ to survive inside a granuloma and overcome stress generated by FQs. Upregulation of PafC under oxidative, nitrostative, and nutrient stress confirmed that through some yet unknown mechanism, PafC is involved in the efficient survival of mycobacteria intracellularly (-Fig. 1C). The TB granuloma inside lungs harbors a pretty rough environment. It is technically a defense mechanism employed by host to contain the mycobacterial infection. There is a high influx of cytokines and neutrophils; oxidative stress in the form of ROS, RNIs, low pH, and oxygen is observed. Despite such harsh conditions MTB is able to successfully survive inside a granuloma and only cause active disease in case of host's immunosuppression. Such persisters are a huge problem in treating TB, as treating latent infection requires a very high dose of antibiotics which in itself has severe side effects. Treating MTB in its active state is relatively easier. To the best of our knowledge so far there is no literature citing a direct role of pafC in allowing MTB to survive under stress.

Role of pafBC transcript has been reported in mediating DNA repair mechanism through lexA independent pathway. pafBC functions as transcription factor and mediates the SOS DNA repair inside mycobacteria. ${ }^{16-18}$ But the functioning of PafC in the presence of drugs and its mechanism of action remains to be identified. For the PafC to be effective against FQs, it must allow mycobacteria to survive and resist high concentrations of drug. Overexpressed PafC did indeed render the FQ relatively ineffective in mycobacteria (-Fig. 2A). Efficacy of any drug is dependent on how much of it is getting accumulated inside the pathogen and also whether the pathogen is able to overcome the drug's bactericidal action. DNA gyrase (Topoisomerase II), the major target of FQs, is intracellular and hence FQs need to cross the bacterial cell wall to function and exert an effect. There have not been many studies on the accumulation of FQs in mycobacteria and thereby the role permeability has in imparting drug resistance. ${ }^{19}$ Mycobacteria evolutionarily possess many mechanisms which makes it resistant to drugs. In the series of experiments conducted it was observed that surprisingly MS_OE had reduced intracellular survival than the KD strain upon FQ treatment at different concentrations ( - Fig. 2B-D).
It could have been because of the stalling of bacterial metabolism due to combined effect of on-going DNA repair and increased drug efflux.

Drug efflux pumps form a vital part of xenobiotic metabolism in mycobacteria and the shutdown of metabolism allows mycobacteria to enter a dormant phase. gyrA and gyrB are largely considered the single most important targets of FQs in mycobacteria because mycobacteria possess only these two respective genes which code for DNA gyrase. It is supported more by the fact that mostly the mutations in gyrA and gyrB have been reported during FQ resistance. But it has now been well established that the energy-dependent quinolone efflux also plays part in quinolone resistance in mycobacteria. Decreased FQ accumulation in PafC overexpressing strain showed that PafC rather does increases the drug efflux and is thereby involved in the pathogenicity of mycobacteria (-Fig. 3). Mycobacteria has a slower generation time compared with other pathogens and it also possess a highly complex mycolic acid containing cell wall which gives it the sufficient time to be exposed to subinhibitory drug concentration and in the process acquire drug resistance. ${ }^{29,30}$

The finding that PafC has a necessary part to play in mycobacteria's virulence, prompted us to instigate if indeed the protein is secretory in nature similar to CFP-10/ESAT-6. But since the protein was undetectable at its native size of $33 \mathrm{kDa}$ in the culture filtrates and the patient sera, it was concluded that PafC is a non-secretory protein (-Fig. 4A, B). Nonsecretory nature of PafC could be attributed to the fact that pafC works in association with proteasomal complex that primarily functions in the cytosol. For treating MDR-TB, FQs are given in monotherapy in the current ATT regimen followed. This consequentially increases the chances of drug resistance in mycobacteria. ${ }^{31,32}$ Deciphering the position of PafC in this array it was vindicated that when mycobacteria were treated with FQs in culture and intracellularly, the pafC mRNA expression shot up drastically. Such was not the case when treated with RIF ( - Fig. 4D, E). RIF was taken as a control in our study because it is a major first line TB drug administered to patients. Since we validated our data in patient samples it was essential to confirm the pafC's expression in vitro similar to susceptible TB patients. Higher pafC mRNA expression in MDR cases than XDR cases was an interesting finding. Since at the outset it was hypothesized that DR-TB patients should have a similar pafC expression pattern, but we found that in MDR patients it was around seven times more than the XDR patients. In comparison with susceptible cases it was around 13 times more (-Fig. 4F). MDR patients are treated with FQs and increased pafC mRNA in them means that it is specifically regulated by FQs. In XDR patients though the pafC mRNA expression was higher than susceptible cases it was much less than the MDR cases. The bacteria in the XDR cases are already resistant to FQs, hence there was an increased expression in comparison with drug-susceptible cases. But since there was no continuous exposure to FQs, the pafC mRNA expression was relatively subsided.

Patients selected for the study had certain inclusion and exclusion criteria based on the absence or presence of any other disease with immune suppression, age or, EPTB. Patients 
with metabolic disorders like diabetes mellitus (DM) were not included in the study since they already have a suppressed immunity and behavior of MTB changes under such conditions. Two crucial drugs RIF and INH used in the treatment of TB interact with oral antidiabetic drugs and therefore may lead to suboptimal glycemic control, reducing the effectiveness of DM management. ${ }^{33,34}$ The bidirectional association between TB and DM is currently one of the major concerns for clinicians. The data in the study conducted by Siddiqui et al in 2016 showed that PTB patients with DM have reduced rate of sputum conversion with higher probability of poor treatment outcome, namely, default, death, failure, and shifting to MDR category, than patients without DM. ${ }^{35}$ Altered plasma levels of TB drugs due to differences in absorption, distribution, metabolism, and/or excretion of drugs in diabetic patients complicate the course of treatment of TB in people with diabetes. Same is the case with HIV + patients. Complex pharmacokinetic drugdrug interactions between the rifamycins and two widely used classes of antiretroviral drugs the protease inhibitors and the non-nucleoside reverse-transcriptase inhibitors decrease plasma concentrations of several antiretroviral drugs. ${ }^{36}$ This leads to a loss of antiviral efficacy and stepwise accumulation of resistance mutations ${ }^{37}$. A retrospective study of TB patients in Canada found that in comparison with HIV-cases, the HIV+ patients are 3.8 times more likely to experience a significant drug-related adverse event. ${ }^{38}$

An interesting or rather a known feature observed during our study was that the number of female patients enrolled for the study was less than the half of male patients. This was most probably due to the socio-economic barrier which women still encounter, especially in a country like ours. Fear of being left out or being called a social outcast makes women from weaker economic background hide the disease.

Considering the damage FQs cause to mycobacteria plus the increased PafC expression in mycobacteria under FQ generated stress and otherwise, we tested the mRNA expression profile of two of the major DNA damage repair enzyme, RecA and LexA. PafC overexpression strain showed marked increase in the mRNA levels of these two enzymes in comparison with KD and MS_VEC (-Fig. 5A, B). The mRNA expression profiles of lexA and recA followed the mRNA expression profile of pafC in PTB patients, i.e., they were significantly increased in the DR patients especially the MDR patients ( $\mathbf{- F i g}$. 5C, D). LexA is a known inhibitor of RecA; under normal conditions it binds to the SOS box thereby preventing the transcription of DNA repair enzymes. ${ }^{16,17}$ During SOS repair, autolysis of LexA leads to the transcription of DNA repair genes mediated by RecA. Increased number of recA transcripts in PafC MS_OE and decrease in MS_ KD upon FQ treatment indicate the correlation between the two. In the control strain the relative mRNA level of lexA was either more than or equal to recA (upon FQ treatment). But when the drugs were administered the levels of recA mRNA transcripts shot up exponentially ( $\mathbf{- F i g}$. $\mathbf{5 C}$, D). In mycobacteria the DNA damage repair is mediated via lexA-dependent and lexA-independent pathways. lexA-independent (via P1 promoter) pathway is the major pathway involved, as could be deciphered from our results as well. Upon FQ treatment though both lexA and rec $A$ increased but the increase in recA mRNA levels was around ten times more than lexA. A recent study done in Arthrobacter aurescens PafBC characterizes the role of this heterodimer as a transcriptional regulator. Presence of WYL domain and winged helix turn helix in PafC points out its mode of action as a transcriptional regulator. ${ }^{18}$ Only recently it was reported that pafBC acts a transcriptional regulator of PafA, the prokaryotic counterpart of E3 ubiquitin ligase. pafBC acts as a positive regulator for PafA and that it is essential for the recovery from DNA damaging conditions in MSMEG. ${ }^{38}$ The clinical data analysis from different types of TB patients specifically highlights the functioning of pafC in the presence of FQs at the transcriptional level.

\section{Conclusion}

Tuberculosis is a disease dreaded worldwide, mostly because of the ability of MTB to evolve continuously together with its host. Proteasomes are the necessary machinery required by both eukaryotes and prokaryotes for their respective survival. It is all the more essential for mycobacteria since they play a prominent role in imparting pathogenicity to it. Mycobacteria contain a pup which targets the intrinsic and extrinsic proteins for degradation. Though functionally pup is similar to Ub in eukaryotes, architecturally it is very different. Also unlike in eukaryotes where there are more than one Ub ligases present, mycobacteria, so is known to contain only one in the form of PafA. PafA functions as E3 ligase and tags the substrate at cysteine moiety for proteasomal degradation. pafA is a part of paf operon which also has two other genes, namely, pafB and pafC. Our study on pafC showed that PafC operates to impart resistance to mycobacteria by increasing the drug efflux and by regulating the DNA damage repair. The drug efflux pumps wear down the effect of drugs by pumping them out of the bacterial system, a mechanism which is utilized by PafC overexpressing strains. Increased internalization of the bacteria helps it to avoid the stress generated by the FQs to a certain extent. In an event of FQ generated stress, the PafC overexpression counters it by effluxing the drug from the mycobacteria and the increased engulfment aids in acquiring the latency under unfavorable conditions. Both these events help mycobacteria in establishing a successful infection (-Fig. 6). Mycobacteria when in latent state, slows down its metabolism and only becomes active if and when the immune status of the host deteriorates.

An observational analysis of patients recruited in the study pointed at the lesser amount of TB notification from females. It highlights the socio-economic and psychological barrier prevalent amongst the females. Ours was the study targeting the functioning of PafC in the presence of FQs. It was a pilot study and to the better of our knowledge first study to examine the status of pafC in the clinical isolates of TB patients. The clinical data generated here validated the in vitro studies done with OE and KD strains of pafC in MSMEG.

\section{Acknowledgments}

The authors acknowledge Dr. Kishore K. Srivastava, Senior Principal Scientist and Chairperson, Division of Microbiology, CSIR (Central Drug Research Institute) for providing the laboratory infrastructure to carry out the 


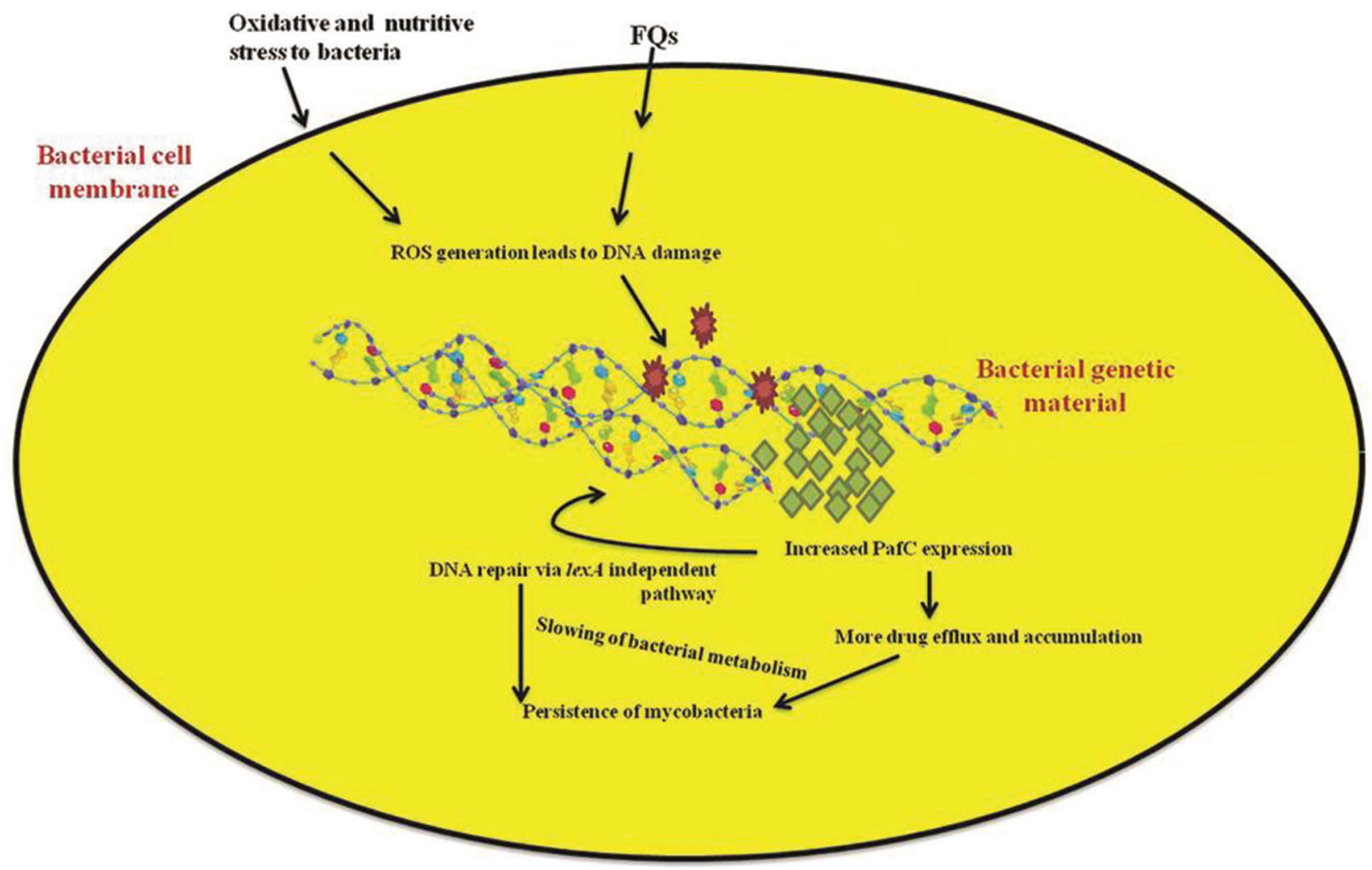

Fig. 6 Pictorial representation of functioning of PafC. Upon oxidative stress the DNA damage in mycobacteria leads to the increased PafC expression. This increased expression enhances the efflux of drugs and DNA damage repair via lexA-independent pathway. Both these mechanisms slow down the metabolic rate in mycobacteria which ultimately caused the slow growth but increased intracellular survival of the mycobacteria. DNA, deoxyribonucleic acid; PafC, proteasome accessory factor-C.

molecular biology work. We would also like to thank all the patients who participated in the study

\section{Author'sContribution}

A.N. conducted the literature review, conceptualization of work, acquiring clinical samples, all experimentation, manuscript drafting, writing, and editing. R.K.D. performed experiments with mycobacterial growth and intracellular survival, providing J774A.1 cell line, held discussions concerning the work and manuscript preparation, manuscript writing and editing. A.K.V. and A.S. did the manuscript editing, held discussions concerning work, and did the manuscript preparation. S.K. did the conceptualization of work, held discussions concerning the work and manuscript preparation, acquired clinical samples and worked on the manuscript editing.

\section{Declaration}

Ethical approval for the study was granted by Research Cell, King George's Medical University, Uttar Pradesh, Lucknow Institutional Ethics Committee (IEC) [576/Ethics/R.cell-16 dated 26/10/2016].

\section{References}

1 World Health Organization. Global TB report. Available at: https://www.who.int/teams/global-tuberculosis-programme/ tb-reports/global-report-2019. Accessed December 21, 2020

2 Raja A. Immunology of tuberculosis. Indian J Med Res 2004;120(4):213-232

3 Silva Miranda M, Breiman A, Allain S, Deknuydt F, Altare F. The tuberculous granuloma: an unsuccessful host defence mechanism providing a safety shelter for the bacteria? Clin Dev Immunol 2012;2012:139127

4 Viveiros M, Leandro C, Amaral L. Mycobacterial efflux pumps and chemotherapeutic implications. Int J Antimicrob Agents 2003;22(3):274-278

5 Andriole VT. The quinolones: past, present, and future. Clin Infect Dis 2005;41(2, suppl 2):S113-S119

6 Nguyen L. Antibiotic resistance mechanisms in M. tuberculosis: an update. Arch Toxicol 2016;90(7):1585-1604

7 Devasia RA, Blackman A, Gebretsadik T, et al. Fluoroquinolone resistance in Mycobacterium tuberculosis: the effect of duration and timing of fluoroquinolone exposure. Am J Respir Crit Care Med 2009;180(4):365-370

8 Malik S, Willby M, Sikes D, Tsodikov OV, Posey JE. New insights into fluoroquinolone resistance in Mycobacterium tuberculosis: functional genetic analysis of gyrA and gyrB mutations. PLoS One 2012;7(6):e39754 
9 Kohanski MA, Dwyer DJ, Hayete B, Lawrence CA, Collins JJ. A common mechanism of cellular death induced by bactericidal antibiotics. Cell 2007;130(5):797-810

10 Striebel F, Imkamp F, Özcelik D, Weber-Ban E. Pupylation as a signal for proteasomal degradation in bacteria. Biochim Biophys Acta 2014;1843(1):103-113

11 Becker SH, Darwin KH. Bacterial proteasomes: mechanistic and functional insights. Microbiol Mol Biol Rev 2016;81(1):1-20

12 Zhang S, Burns-Huang KE, Janssen GV, et al. Mycobacterium tuberculosis proteasome accessory factor a (pafa) can transfer prokaryotic ubiquitin-like protein (pup) between substrates. MBio 2017;8(1):e00122-e17

13 Pearce MJ, Mintseris J, Ferreyra J, Gygi SP, Darwin $\mathrm{KH}$. Ubiquitin-like protein involved in the proteasome pathway of Mycobacterium tuberculosis. Science 2008;322(5904):1104-1107

14 Festa RA, McAllister F, Pearce MJ, et al. Prokaryotic ubiquitin-like protein (Pup) proteome of Mycobacterium tuberculosis. PLoS One 2010;5(1):e8589

15 Festa RA, Pearce MJ, Darwin KH. Characterization of the proteasome accessory factor (paf) operon in Mycobacterium tuberculosis. J Bacteriol 2007;189(8):3044-3050

16 Olivencia BF, Müller AU, Roschitzki B. Burger S, Weber-Ban E, Imkamp F. Mycobacterium smegmatis PafBC is involved in regulation of DNA damage response. Sci Rep 2017;7(1):1-13

17 Müller AU, Imkamp F, Weber-Ban E. The mycobacterial LexA/RecA-independent DNA damage response is controlled by pafbc and the pup-proteasome system. Cell Rep 2018;23(12):3551-3564

18 Müller AU, Leibundgut M, Ban N, Weber-Ban E. Structure and functional implications of WYL domain-containing bacterial DNA damage response regulator PafBC. Nat Commun 2019;10(1):4653

19 Piddock LJV, Ricci V. Accumulation of five fluoroquinolones by Mycobacterium tuberculosis H37Rv. J Antimicrob Chemother 2001;48(6):787-791

20 Ahmad S. Pathogenesis, immunology, and diagnosis of latent Mycobacterium tuberculosis infection. Clin Dev Immunol 2011;2011:814943

21 Fonseca JD, Knight GM, McHugh TD. The complex evolution of antibiotic resistance in Mycobacterium tuberculosis. Int J Infect Dis 2015;32:94-100

22 Malinga LA, Stoltz A. Efflux pump mediated second-line tuberculosis drug resistance. Mycobact Dis 2016;6(3):1-9

23 da Silva PE, Von Groll A, Martin A, Palomino JC. Efflux as a mechanism for drug resistance in Mycobacterium tuberculosis. FEMS Immunol Med Microbiol 2011;63(1):1-9

24 Smith T, Wolff KA, Nguyen L. Molecular biology of drug resistance in Mycobacterium tuberculosis. Curr Top Microbiol Immunol 2013;374:53-80

25 Trauner A, Borrell S, Reither K, Gagneux S. Evolution of drug resistance in tuberculosis: recent progress and implications for diagnosis and therapy. Drugs 2014;74(10):1063-1072
26 Ginsburg AS, Hooper N, Parrish N, et al. Fluoroquinolone resistance in patients with newly diagnosed tuberculosis. Clin Infect Dis 2003;37(11):1448-1452

27 Li Q Xie L, Long Q et al. Proteasome accessory factor C (pafC) is a novel gene involved in Mycobacterium intrinsic resistance to broad-spectrum antibiotics-fluoroquinolones. Sci Rep 2015;5:11910

28 Williams DL, Torrero M, Wheeler PR, et al. Biological implications of Mycobacterium leprae gene expression during infection. J Mol Microbiol Biotechnol 2004;8(1):58-72

29 Gillespie SH, Basu S, Dickens AL, O'Sullivan DM, McHugh TD. Effect of subinhibitory concentrations of ciprofloxacin on Mycobacterium fortuitum mutation rates. J Antimicrob Chemother 2005;56(2):344-348

30 Walter ND, Dolganov GM, Garcia BJ, et al. Transcriptional adaptation of drug-tolerant Mycobacterium tuberculosis during treatment of human tuberculosis. J Infect Dis 2015;212(6):990-998

31 Von Groll A, Martin A, Jureen P, et al. Fluoroquinolone resistance in Mycobacterium tuberculosis and mutations in gyrA and gyrB. Antimicrob Agents Chemother 2009;53(10):4498-4500

32 Miotto P, Cirillo DM, Migliori GB. Drug resistance in Mycobacterium tuberculosis: molecular mechanisms challenging fluoroquinolones and pyrazinamide effectiveness. Chest 2015; 147(4):1135-1143

33 Kant S, Lata H, Natu SM, Mishra AK, Verma NS. Diabetes mellitus with pulmonary tuberculosis-a double trouble. J Indian Med Assoc 2013;111(3):187-191

34 Nijland HMJ, Ruslami R, Stalenhoef JE, et al. Exposure to rifampicin is strongly reduced in patients with tuberculosis and type 2 diabetes. Clin Infect Dis 2006;43(7):848-854

35 Siddiqui AN, Khayyam KU, Sharma M. Effect of Diabetes Mellitus on Tuberculosis Treatment Outcome and Adverse Reactions in Patients Receiving Directly Observed Treatment Strategy in India: A Prospective Study. Biomed Res Int 2016;2016:7273935

36 González de Requena D, Bonora S, Garazzino S, et al. Nevirapine plasma exposure affects both durability of viral suppression and selection of nevirapine primary resistance mutations in a clinical setting. Antimicrob Agents Chemother 2005;49(9):3966-3969

37 Yee D, Valiquette C, Pelletier M, Parisien I, Rocher I, Menzies D. Incidence of serious side effects from first-line antituberculosis drugs among patients treated for active tuberculosis. Am J Respir Crit Care Med 2003;167(11):1472-1477

38 Korman M, Elharar Y, Fishov I, Gur E. The transcription of pafA, encoding the prokaryotic ubiquitin-like protein ligase, is regulated by PafBC. Future Microbiol 2019;14(1):11-21 